\title{
The pretreatment of corn stover with Gloeophyllum trabeum KU-41 for enzymatic hydrolysis
}

\author{
Ziqing Gao, Toshio Mori and Ryuichiro Kondo*
}

\begin{abstract}
Background: Pretreatment is an essential step in the enzymatic hydrolysis of biomass for bio-ethanol production. The dominant concern in this step is how to decrease the high cost of pretreatment while achieving a high sugar yield. Fungal pretreatment of biomass was previously reported to be effective, with the advantage of having a low energy requirement and requiring no application of additional chemicals. In this work, Gloeophyllum trabeum KU-41 was chosen for corn stover pretreatment through screening with 40 strains of wood-rot fungi. The objective of the current work is to find out which characteristics of corn stover pretreated with G. trabeum KU-41 determine the pretreatment method to be successful and worthwhile to apply. This will be done by determining the lignin content, structural carbohydrate, cellulose crystallinity, initial adsorption capacity of cellulase and specific surface area of pretreated corn stover.
\end{abstract}

Results: The content of xylan in pretreated corn stover was decreased by $43 \%$ in comparison to the untreated corn stover. The initial cellulase adsorption capacity and the specific surface area of corn stover pretreated with $G$. trabeum were increased by 7.0 - and 2.5 -fold, respectively. Also there was little increase in the cellulose crystallinity of pretreated corn stover.

Conclusion: G. trabeum has an efficient degradation system, and the results indicated that the conversion of cellulose to glucose increases as the accessibility of cellulose increases due to the partial removal of xylan and the structure breakage of the cell wall. This pretreatment method can be further explored as an alternative to the thermochemical pretreatment method.

Keywords: Brown-rot fungus, Gloeophyllum trabeum, Corn stover, Bio-ethanol

\section{Background}

Corn stover, the residue left in the field following the harvest of cereal grain, is a very common agricultural product in areas with high levels of corn production. The current annual production of corn stover is about $250 \mathrm{M}$ tons in the U.S. [1] and $220 \mathrm{M}$ tons in China [2]. Corn stover is in many ways an ideal feedstock for biomass ethanol production. Although biomass ethanol can be made from a wide range of biomass materials, stover from existing corn production is by far the most abundant crop residue readily available today.

Biomass ethanol is ethanol made from non-grain plant materials known as biomass. The bulk of most plants is

\footnotetext{
* Correspondence: ryukondo@agr.kyushu-u.ac.jp

Department of Agro-Environmental Sciences, Faculty of Agriculture, Kyushu, University, 6-10-1 Hakozaki, Higashi-ku, Fukuoka, 812-8581, Japan
}

fibrous material consisting of cellulose, hemicellulose and lignin. The bioconversion of biomass to ethanol requires hydrolysis of the carbohydrate polymers, cellulose changes to its constituent monomeric sugars prior to microbial fermentation. Due to the complicated structure of the cell wall in biomass, additional pretreatment is needed for biomass ethanol production compared to grain ethanol.

Biomass pretreatment is an essential step in biomass ethanol production with high yield [3,4]. Many studies have been published about different pretreatment methods for enhancing the digestibility of biomass $[5,6]$. Biological pretreatment that utilizes the metabolite of microorganism in nature to break up the cell wall of biomass for ethanol production is a promising technology due to its advantages of having a low energy requirement

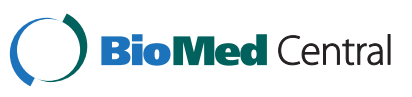


and being friendly to the environment $[7,8]$. Compared to chemical pretreatment, it is no need to recycle the chemical and does not bring exotic materials to environment. These reductions in the severity of pretreatment conditions could result in less biomass degradation and consequently lower inhibitor concentrations compared to conventional thermochemical pretreatment [5]. Fungal pretreatment using wood-rot fungus is one of the most effective methods for enhancing the efficiency of enzymatic saccharification [9-12]. Fissore et al [13] evaluated a process of combined brown-rot decay -chemical delignification as a pretreatment for bioethanol production. The combination of brown-rot fungi and organosolv processes result in $210 \mathrm{ml}$ ethanol/ $\mathrm{kg}$ wood. Some thermochemical pretreatment methods have been performed for biomass ethanol production [4,14-17]. However, biological pretreatment of corn stover with wood-rot fungi has been neglected. As is widely known, due to the ability to degrade lignin extensively, white-rot fungi (WRF) have received considerable attention for their potential to remove lignin for bio-ethanol pretreatment [8]. In contrast, brown-rot fungi (BRF) such as Gloeophyllum trabeum, have different mechanisms for the degradation of wood that rapidly depolymerize the cellulose and hemicellulose in wood with modified lignin in the brown residue. BRF degrade lignocellulose via a theorized two-part mechanism, with modification of the plant cell wall induced nonenzymatically and secretion of cellulases and hemicellulases likely occurring after modifications $[18,19]$. The initial stages of decay are thought to involve Fenton chemistry $\left(\mathrm{Fe}^{2+}+\mathrm{H}_{2} \mathrm{O}_{2}\right)$ for the production of hydroxyl anions and radicals [20]. The low molecular weight reactants, unlike enzymes, are small enough to penetrate the wood lignocellulose fabric, and have been shown in immunolabeling studies to be present throughout the $\mathrm{S} 2$ layer of the brown rot-degraded cell wall [21]. Cellulase production by brown rot fungi is different in that it is typically constitutive, not influenced by free glucose concentrations, and most often lacks exo-acting cellobiohydrolase [22,23]. G. trabeum has the ability of fermenting sugar to ethanol [24]. The enzymatic and non-enzymatic mechanisms used by G. trabeum to degrade wood could potentially be employed for the bioconversion of other biomass, such as corn stover. The complicated structural modification of the cell wall plays a role in the initial degradation of BRF in the pretreatment for the purpose of bio-ethanol production.

In this study, 40 strains of wood-rot fungi (33 strains of WRF and 7 strains of BRF) were screened for corn stover pretreatment. A strain of brown-rot fungus KU-41 was selected for corn stover pretreatment due to its having the highest conversion of cellulose to glucose (CCG). A molecular biological identification showed that KU-41 was most closely related to Gloeophyllum trabeum. To gain a deeper understanding of the mechanisms of brown-rot fungus pretreatment, the fungal-pretreated corn stover was evaluated in detail, including the lignin and structural carbohydrate contents, cellulose crystallinity, initial adsorption capacity of cellulase, SEM and specific surface area.

\section{Results}

\section{Fungal screening}

The CCG results of the pretreatment of corn stover with wood-rot fungi after $48 \mathrm{~h}$ of hydrolysis are shown in Figure 1. Compared to the control, the CCG levels of corn stover pretreated with most white-rot fungi were not increased except in those pretreated by Pycnoporus coccineus, $\mathrm{W}_{2}$ and $\mathrm{W}_{3}$, but this increase of CCG was not significant. We tried to use 7 strains of brown-rot fungi, which had the ability to decay wood significantly. The CCG of corn stover was not increased by pretreatment with these brown-rot fungi except for G. trabeum NBRC6509 and KU-41. In particular, the fungus KU-41 enhanced the CCG of corn stover. The CCG of pretreated corn stover was determined by the glucose yield and weight loss. Although some strains of wood-rot fungi have great degrading ability, they were not suitable for corn stover pretreatment due to the simultaneous degradation of cellulose. Of these 40 strains of wood-rot fungi, KU-41 caused the greatest increase in CCG. Therefore, KU-41 was selected for further study in order to evaluate its use in corn stover pretreatment.

\section{Fungal identification}

Sequencing of the ITS rDNA region of KU-41 was performed, and the ITS sequence was submitted to Genbank with the accession number JF682770-JF682771. The strain showed the highest identity (99\%) with $G$. trabeum. Based on the comparison of the ITS rDNA gene sequences, the strain chosen for corn stover pretreatment was identified as a strain of G. trabeum and was named G. trabeum KU-41. We chose another strain of G. trabeum NBRC6430 to pretreat the corn stover, and compared the efficiency of this pretreatment to that of G trabeum KU-41.

\section{Pretreatment conditions and enzymatic hydrolysis}

In the process of corn stover pretreatment with wood-rot fungi, moisture content and pretreatment period were important factors that affected the efficiency of pretreatment. The effect of moisture content on the pretreatment period and the CCG of corn stover pretreated with KU-41 was tested (data not shown). The highest CCG was obtained after 20-day pretreatment with $80 \%$ moisture content. The efficiency of pretreatment was evaluated by enzymatic hydrolysis. Figure 2 shows enzymatic hydrolysis of the samples after $48 \mathrm{~h}$. As expected, corn stover without pretreatment was capable of converting cellulose into glucose with an efficiency of $38.7 \%$. High glucose yields 


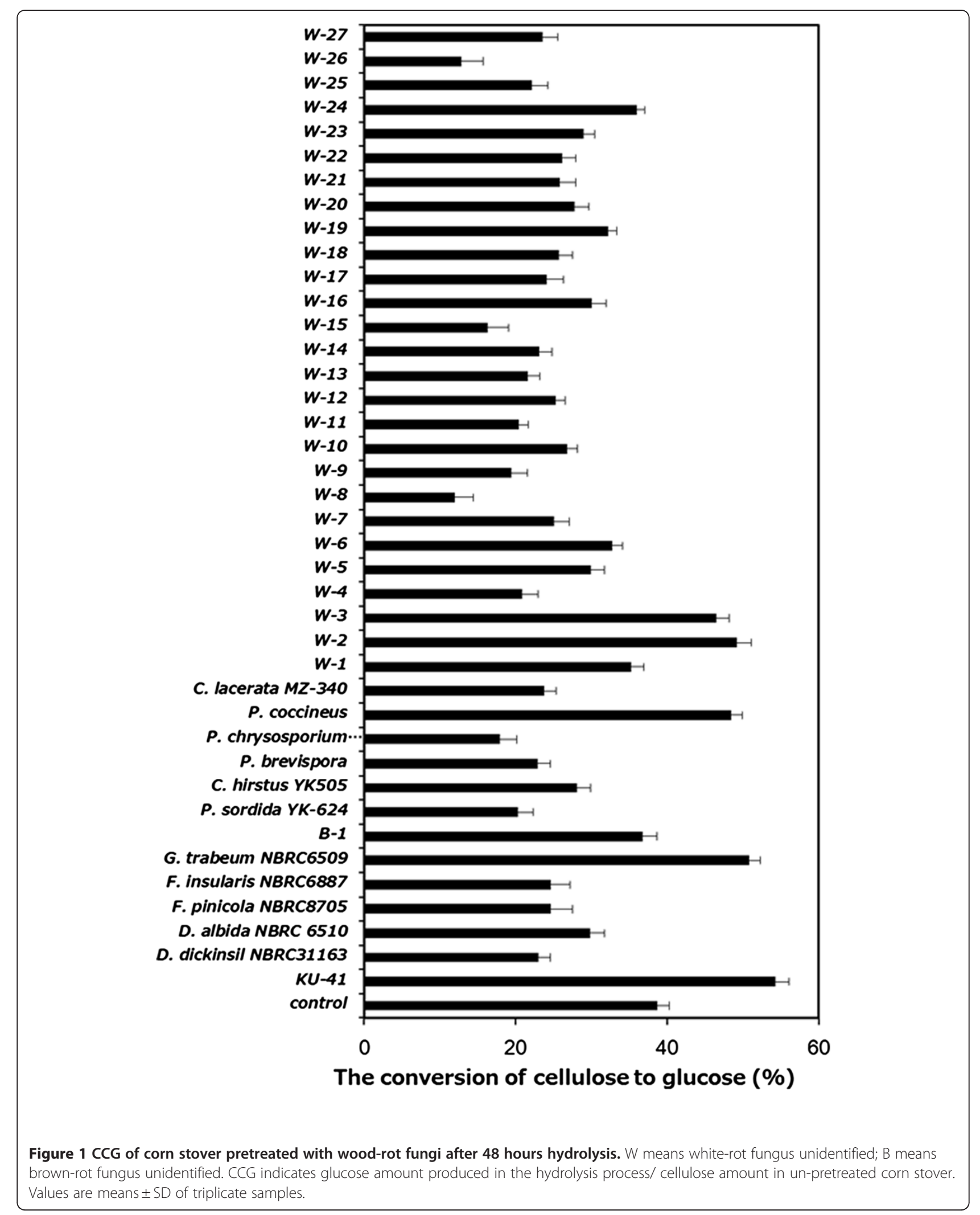




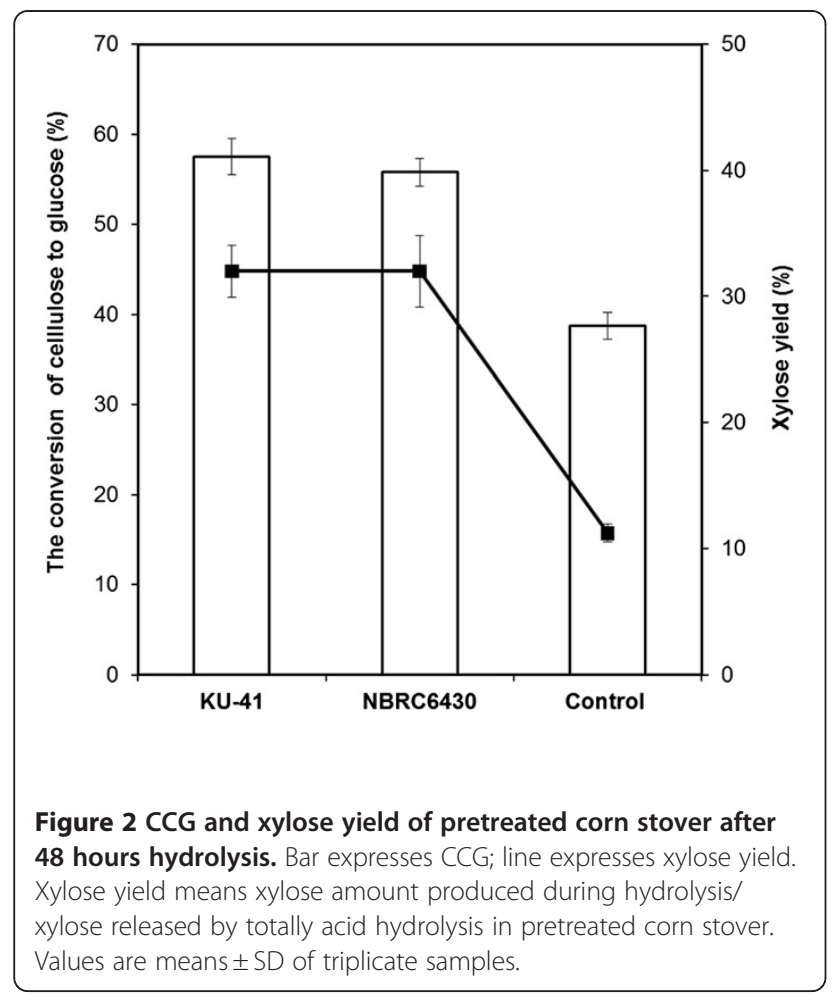

were obtained when the corn stover was pretreated by KU-41 and NBRC6430. The CCG levels increased by $47 \%$ and $42 \%$ over 20-day treatment with KU-41 and NBRC6430,respectively. The strain of G. trabeum KU-41 seemed to be the most promising fungus for biological pretreatment of corn stover.

Hemicellulose serves as a connection between lignin and cellulose fibrils and gives the whole cellulosehemicellulose-lignin network more rigidity [25]. Xylan is the main component of hemicellulose in corn stover. In corn stover pretreated with KU-41 and NBRC6430, 32.0\% and $31.4 \%$ xylan was transformed into xylose and released after $48 \mathrm{~h}$ of hydrolysis, in comparison with only $11.2 \%$ xylan transformation in the un-pretreated sample (Figure 2). The xylose yield in the saccharification solution of pretreated corn stover was 2.8-fold greater than that of the un-pretreated sample suggested that during corn stover pretreatment with G. trabeum, the hemicellulose structure modification or breakage is beneficial for xylose release during enzymatic hydrolysis. An increase in xylose release led to an increase in cellulose accessibility, which consequently resulted in the glucose yield increasing in corn stover pretreated by G. trabeum KU-41and G. trabeum NBRC6430.

\section{Compositional analysis}

Compositional analysis of corn stover pretreated with fungus (Table 1) gave a good indication of the possible changes in the different components. As the pretreatment progressed, hemicellulose was the component that was removed in the greatest proportion. Biodegradation of hemicellulose from corn stover was $43 \%$ with G. trabeum KU-41 and 43\% with G. trabeum NBRC6430. As hemicellulose is connected with cellulose microfibrils, the prior removal of these can facilitate cellulose degradation. The content of glucan decreased slightly, reaching removal percentages of $16.8 \%$ and $18.3 \%$ with G. trabeum KU-41 and G. trabeum NBRC6430, respectively. Consistent with the degradation mechanism of brown-rot fungi, lignin was essentially undegraded by the two strains of G. trabeum.

\section{Crystallinity determination}

Lignocellulosic biomass is mainly composed of cellulose (amorphous and crystalline), hemicellulose and lignin. Crystallinity is believed to affect enzymatic saccharification of cellulose [25]. However, due to the complex structure of the cell wall in lignocellulosic biomass, it is impossible to separate cellulose from other components completely or to measure the cellulose crystallinity directly. X-ray measurement of $\mathrm{CrI}$ is still the most frequently-used method to estimate the effect of pretreatment on biomass crystallinity. The CrI values of pretreated corn stover samples here were determined by measuring the relative amount of crystalline cellulose in the total solid. The cellulose crystallinity $(\mathrm{CrI} \%)$ in corn stover pretreated with G. trabeum KU-41(55.3 \pm 0.02$)$ and G. trabeum NBRC6430 (55 \pm 1.37$)$ was slightly increased compared to the control $(53.9 \pm 2.01)$. The slight increase of $\mathrm{CrI}$ in the pretreated samples suggested that the cellulose became more exposed after pretreatment. However, all materials give rise to X-ray scattering, with the amorphous part

Table 1 Main composition of unpretreated and pretreated corn stover and ratio of component left after pretreatment

\begin{tabular}{|c|c|c|c|c|c|c|}
\hline \multirow[t]{2}{*}{ Pretreatment } & \multicolumn{3}{|c|}{$\begin{array}{c}\text { Composition of pretreated } \\
\text { corn stover (\%) }\end{array}$} & \multicolumn{3}{|c|}{$\begin{array}{l}\text { Ratio of component left in } \\
\text { pretreated corn stover (\%) }\end{array}$} \\
\hline & $\bar{G}$ & $x$ & $L+A$ & $\bar{G}$ & $x$ & $L+A$ \\
\hline G. trabeum KU-41 & 39.1 & 12.0 & 33.0 & 83.2 & 57.0 & 96.1 \\
\hline G. trabeum NBRC 6430 & 38.4 & 12.0 & 33.3 & 81.7 & 57.0 & 97.0 \\
\hline Control & 35.7 & 16.0 & 26.1 & 100.0 & 100.0 & 100.0 \\
\hline
\end{tabular}


including not only amorphous cellulose but also hemicellulose and lignin. Hemicellulose and lignin have been determined to have diffractograms similar to amorphous cellulose [26], giving wide unspecific peaks, which may affect the results.

\section{Initial adsorption capacity}

Jeoh et al. [27] claimed that the hydrolysis rate and/or yield is directly related to the amount of adsorbed enzymes. Figure 3 shows the initial adsorption capacity of cellulase onto corn stover after pretreatment with $G$. trabeum. The pretreated corn stover showed a significant increase of the initial adsorption capacity. The initial adsorption capacity increased about 7 -fold after pretreatment with G. trabeum. Lignin is believed to impede enzyme access to glucan chains by its binding and steric hindrance $[28,29]$. In this study, the lignin ratio in corn stover pretreated with G. trabeum KU-41 increased by $30 \%$ (Table 1 ), while the CCG was enhanced by $46 \%$ (Figure 2). Evidently, the lignin content is not the main reason of the increase of the cellulase initial adsorption capacity in corn stover pretreated with G. trabeum. Kumar and Wyman [6] proposed that lignin did not directly control the cellulose accessibility but restricted the xylan accessibility, which in turn controlled access to cellulose. The xylose yield of pretreated corn stover increased 2.8-fold (Figure 2). So we have reason to believe that the relationship among lignin, hemicellulose and cellulose changed such that the lignin influence was weakened in cellulose hydrolysis during the process of corn stover pretreatment with G. trabeum KU-41 and G. trabeum NBRC6430.

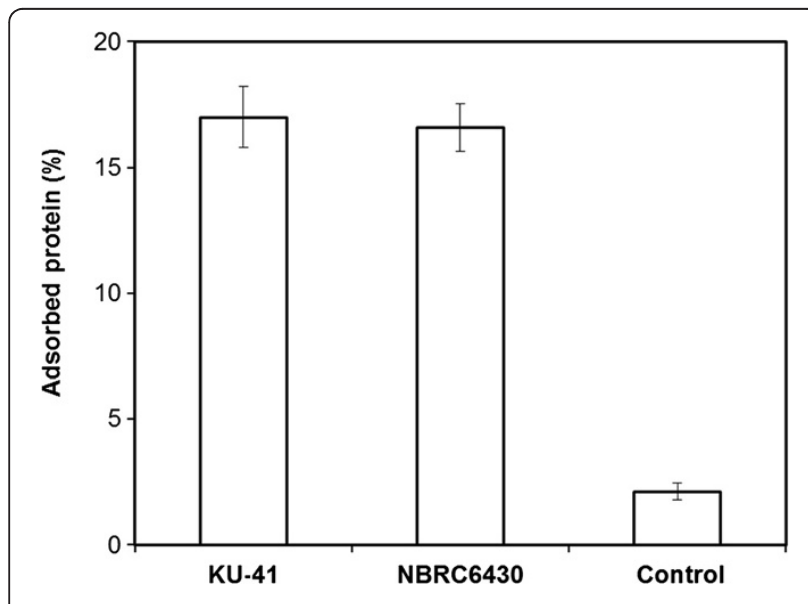

Figure 3 Initial adsorption capacity of cellulase onto corn stover after pretreatment with G. trabeum. Values are means \pm SD of triplicate samples.

\section{Microstructure analysis}

SEM images of corn stover pretreated with fungus are shown in Figure 4 at magnifications of 500 and 1000. The surface of the untreated corn stover was compact and rigid, suggesting that this property hinders the accessibility of cellulase to cellulose (Figure 4E-F). More pores and cracks were created on the surface of the corn stover (Figure 4A-B, 4 C-D), and fungal pretreatment seemed to disrupt the biomass structure to some extent.

The specific surface area and pore distribution are generally considered to play important roles in accessibility. It has been reported that the cellulase digestibility of pretreated biomass is limited by cellulose accessibility [27]. Here (Figure 5), a significant difference in the specific area between the control value and that of pretreatment samples was determined. The specific surface of corn stover pretreated with G. trabeum was increased 2.5-fold.

Based on comprehensive analysis of Figures 4 and 5, the SEM demonstrated that the fungal pretreatment could cause severe degradation and evident damage to the intact cell structure. Both the selective biodegradation of cellulose and hemicellulose components by the fungus and fungal penetration might contribute to the pore production. Removal of hemicellulose increased the mean pore size of the substrate and therefore increased the probability of the cellulose to be hydrolyzed [30,31]. Drying of the pretreated lignocellulose can cause a collapse in pore structure, resulting in decreased enzymatic hydrolysis [32]. Cellulosic particles have both external and internal surfaces. The internal surface area of porous cellulose particles depends on the capillary structure and includes intraparticulate pores $(1-10 \mathrm{~nm})$ as well as interparticulate voids [33]. External surface area is closely related to shape and particle size, and can be estimated by microscopic observation [34]. Zhang and Lynd [35] suggested that cellulase can get trapped in the pores if the internal area is much larger than the external area, which is the case for much lignocellulosic biomass. Pore production, which was a result of the pretreatment, led to a significant increase in specific surface area. These phenomena are probably the reasons that the CCG of corn stover pretreated with $G$. trabeum was enhanced compared to the control.

\section{Discussion}

Fungal pretreatment followed by thermochemical pretreatment could potentially lower the severity requirements of acid, temperature and pressure in thermochemical pretreatment [5]. Lower pretreatment severity is expected to translate directly into lower chemical consumption, and because of lower temperature requirements, possibly lower steam cost. These reductions in severity could also reduce the capital costs and result in lower biomass degradation and consequently lower inhibitor levels. This potential of 

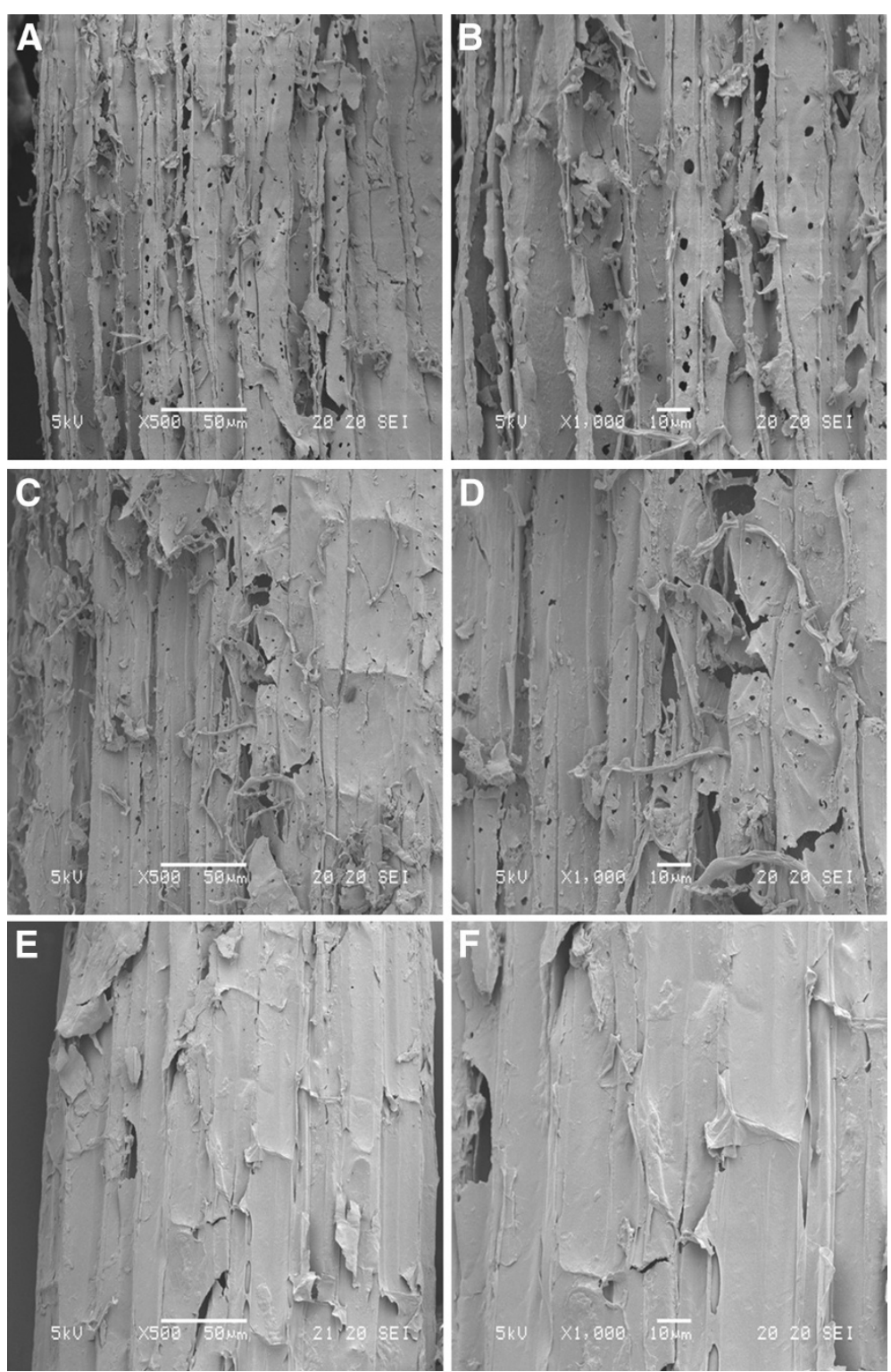

Figure 4 SEM images of un-pretreated and pretreated corn stover samples with $G$. trabeum. [A-B] pretreated sample with G. trabeum KU-41 500x (A), 1000x (B); [C-D] pretreated sample with G. trabeum NBRC 6430 500x (C), 1000x (D); [E-F] un-pretreated sample 500x (E), 1000x (F).

fungal pretreatment can be explained by the ability of certain fungi to disrupt the structure of the cell wall, resulting in partial breakdown of the lignin/carbohydrate complex. Lignin is a complex aromatic polymer based on phenylpropane units. It contains few hydrolysable bonds and so it is poorly susceptible to attack by hydrolytic enzymes. Lignin and its associated compounds have been found to inhibit cellulase action [36]. There is evidence that lignin may retard cellulase action by adsorbing cellulase enzyme [37]. Delignification is a method of increasing the biomass susceptibility of hydrolysis. However, some papers reported that attempts to correlate the delignification of biomass to its increasing susceptibility to enzyme digestion were often inconclusive or contradictory depending on variables such as the type of substrate and the pretreatment conditions [38-40]. Stranks [41] has explained why the lignin-holocellulose relationship rather than the lignin concentration was responsible for the effect of the lignin on cellulose saccharification. Wong et al [42] have suggested that lignin distribution maybe as important as accessibility in determining the enzymatic digestibility of pretreated fibers by steam explosion. Gharpuray et al. [43] 


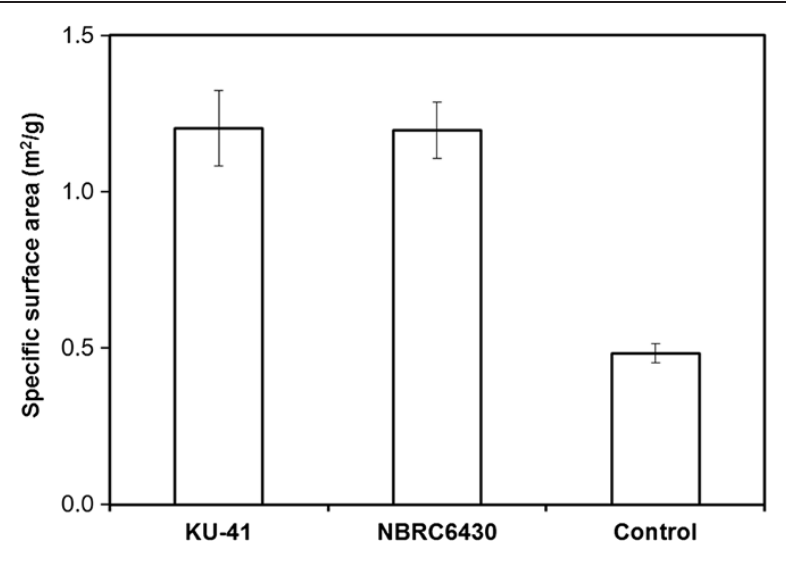

Figure 5 Specific surface area of corn stover pretreated and un-pretreated with $G$. trabeum. Values are means $\pm S D$ of triplicate samples.

also discussed the probable interdependent effects of lignin concentration and surface area on hydrolysis. The complex physical relationship between lignin and cellulose fibrils revealed by Ruel et al. [44] also supports the proposition that lignin distribution is more important to enzymatic hydrolysis than lignin concentration. Yelle et al. [45] reported that brown-rot of spruce wood by Gloeophyllum trabeum resulted in a marked, non-selective depletion of all intermonomer side-chain linkages in the lignin. As shown in Table 1, the lignin ratio in corn stover pretreated with G. trabeum was increased compared to the control. But the CCG (Figure 2) in corn stover pretreated with G. trabeum was enhanced significantly. We believe that the structure of lignin in the process of fungal pretreatment was modified despite the fact that amount was not decreased. The bonds between cellulose and lignin or hemicellulose and lignin were modified or broken [46], which may be one reason that the CCG in corn stover pretreated with G. trabeum KU-41 was enhanced.

The association between the cellulose components and the hemicellulose appears to be of a physical nature, as there have been no reports of chemical bonds between cellulose and hemicellulose molecules. In a series of papers $[37,47,48]$ on the effects of various pretreatments on enzymatic hydrolysis, it was found that in pretreatments which removed only lignin, the rate of digestion of the hemicellulosic component was similar to that of cellulose. This result suggested that the relationship between cellulose and hemicellulose was that one must be removed to facilitate an attack on the other. Increases in cellulose digestibility have been associated with decreased hemicellulose content; more than $80 \%$ of hemicellulose was degraded by a dilute sulfuric acid pretreatment [4]. In this study, $43 \%$ hemicellulose degradation was observed. One interpretation of these data is that removing xylan during pretreatment facilitated cellulase access to the cellulose, which resulted in increased digestibility. This concept has been discussed in the literature as relating changes in the porosity of the biomass sample to digestibility [49]. We believe that the removal of lignin or hemicellulose or both serves one purpose: disruption of carbohydrate-lignin networking, which enhances enzyme adsorption, generally labeled as accessibility.

With lignocellulosic materials, crystallinity appears to be of lesser importance than the association between lignin (and hemicellulose) and surface area. Pretreatments such as ball milling reduced crystallinity but did not have a corresponding effect on hydrolysis [43]. When cardboard and newspaper were used, a decrease in crystallinity resulted in a significant increase in saccharification [50]. With cryomilled rice hulls, the relationship was not apparent [51], while alkali treatment of rice straw resulted in an increase in the crystallinity index from 40 to $52 \%$ and an increase in solubilization from 12 to 63\% [52]. It was also found that the crystallinity of cellulose in wood was not an inhibitory factor in their enzymatic hydrolysis experiments [53]. The effects of various chemical pretreatments on a range of substrates have resulted in no change or an actual increase in crystallinity after the pretreatment, while the rate and extent of enzymatic hydrolysis were markedly increased. Puri [54] concluded that any increase was probably due to the removal of amorphous material rather than any increase in the ordered region and that crystallinity was not as important a factor as generally believed. In this study, Avicel [(R) RH-101 (Sigma)] was used as the sole carbohydrate for cultivating G. trabeum KU-41; the fungus grew very slowly and the crystallinity of Avicel did not change (data not shown). This result was consistent with the finding that most brown-rot fungi showed slow growth on crystalline cellulose despite their rapid degradation of cellulose in wood [55]. The present results indicate that the fungal pretreatment cleavages cellulose in the noncrystalline regions. Part of the amorphous cellulose degradation led to a change of the cellulose structure, which increased the surface area with access to cellulase in pretreated corn stover.

\section{Conclusion}

Although biotechnology presents important opportunities for achieving very low costs, pretreatment of naturally resistant cellulosic materials is essential if we are to achieve high yields from enzymatic hydrolysis. Fungus pretreatment with G. trabeum proved to be an effective way of increasing enzymatic hydrolysis of corn stover for bio-ethanol production. As is widely known, pretreatment with white-rot fungi could increase the enzymatic hydrolysis of biomass through lignin degradation. What happened in the process of pretreatment with brown-rot fungus is 
the crux of this paper. The results showed that the pretreatment by G. trabeum had a partial defibrating effect on corn stover. Partial removal of xylan and modification of the structure of lignin resulted in disrupting the structure of the cell wall. The disruption of the structure of the cell wall increased the accessibility of cellulase to lignocellulose.

A future goal is to improve the efficiency of the fungus pretreatment method described in this study by substantially reducing the cost and accelerating its commercial application. One approach that is attracting attention is the pretreatment of corn stover in vitro with the goal of a short pretreatment time. We believe that with further research and the development of technology, fungus pretreatment could achieve a real decrease in the cost of bio-ethanol production.

\section{Methods}

\section{Fungal stains and isolation}

We selected 33 strains of WRF and 7 strains of BRW that decay wood significantly for use in corn stover pretreatment. Daedalea albida NBRC6510, Daedalea dickinsii NBRC31163, Fomitopsis insularis NBRC6887, Fomitopsis pinicola NBRC8705, Gloeophyllum trabeum NBRC6509 and Phlebia brevispora TMIC33929 were obtained from the Biological Resource Center (Chiba, Japan) and Tottori Mycological Institute (Tottori, Japan). Coriolus hirstus YK-505 [56], Ceriporia lacelate MZ-340 and Phanerochaete sordida YK-624 [57] were obtained from stock cultures in our laboratory. KU-41 and other strains were isolated from decayed wood in a cedar forest at Morotuka, Higashiusuki district, Miyazaki, Japan. Stock cultures of the fungi were maintained on potato dextrose agar (PDA, Difco, Detroit, MI, USA) plates at $4^{\circ} \mathrm{C}$.

\section{Preparation of corn stover}

Corn stover was collected from Yingkou city in Liaoning Province in China. The stover was then chopped air-dried and stored at room temperature. The constituents of corn stover (lignin: 23.3\%, hemicellulose: 28.1\%, cellulose: $35.4 \%$, cell solubles: $12.4 \%$, ash: $2.8 \%$ ) were determined by following a detergent digestion protocol [58]. Before pretreatment, the corn stover was milled and ground to 250-350 $\mu \mathrm{m}$ in size, cleaned with water to remove the soluble content and then filtered, freeze-dried and subjected to treatment with wood-rot fungi.

\section{Fungal screening}

The mycelium was transferred to a new PDA medium in a 9-cm diameter Petri dish and incubated at $30^{\circ} \mathrm{C}$. Once the fungus covered most of the PDA plate, agar plates with mycelium were transferred to a sterile blender cup containing $25 \mathrm{ml}$ of sterile water and homogenized for
$30 \mathrm{~s}$. one milliliter of the white-rot fungus homogenate was used to inoculate $10 \mathrm{ml}$ of low-nitrogen basal III medium [59] and brown-rot fungus homogenate was inoculated into $10 \mathrm{ml}$ potato dextrose broth (PDB) medium in 100-ml Erlenmeyer flasks. When the fungi covered the medium surface, the mixture was vortexed with $25 \mathrm{ml}$ sterile water to $\mathrm{mix}$ it well, and $1 \mathrm{ml}$ was inoculated into $5 \mathrm{~g}$ corn stover powder and then cultivated at $30^{\circ} \mathrm{C}$ for 30 days [5]. Prior to fungal inoculation, the corn stover was sterilized in the autoclave for $20 \mathrm{~min}$ at $121^{\circ} \mathrm{C}$, and then $5 \mathrm{ml}$ of sterilized water was added to the corn stover to keep the moisture content at $50 \%$. Corn stover treated in the same conditions without fungal inoculation was used as the control. After pretreatment, the corn stover was washed to remove the soluble content with $250 \mathrm{ml}$ water, then filtered and freeze-dried. Weight loss was estimated as the difference between the weight of the corn stover at the beginning and at the end of the pretreatment according to the following formula: weight loss $(\%)=\left(W_{1}-W_{2}\right) / W_{1} \times 100$, where $\mathrm{W}_{1}$ is the weight of the sample before pretreatment, and $W_{2}$ represents the weight of the sample after pretreatment. All experiments were performed in triplicate.

\section{Saccharification}

CCG was conducted to estimate the efficiency of the bio-pretreatment. Corn stover without pretreatment was used as the control. A $1 \mathrm{~g}$ corn stover sample with $0.7 \mathrm{~g}$ cellulase T3 (HBI Enzymes Inc. cellulase activity: 240 FPU/g; xylanase activity: $63.62 \mathrm{U} / \mathrm{g}$ ) was added into $50 \mathrm{ml}$ of $0.1 \mathrm{M}$ sodium acetate buffer ( $\mathrm{pH} 4.6)$ and incubated with gentle shaking $(100 \mathrm{rpm})$ at $60^{\circ} \mathrm{C}$. After $48 \mathrm{~h}$, the release of glucose was determined by a Biosensor BF-5 (Oji Scientific Instruments Co., Itd). All experiments were performed in triplicate. Upon evaluation of the effects of pretreatment, CCG was defined as the percentage of cellulose in the raw material converted to glucose, taking into account the weight loss during pretreatment.

\section{Identification of microorganism}

The ITS1-5.8-ITS2 ribosomal RNA gene of KU-41 was amplified by PCR using the primer set ITS1 primer (5'TCCGTAGGTGAACCTGCGG-3') and ITS4 primer (5'TCCTCCGCTTATTGATATGC-3'). The 626-bp amplicon obtained was cloned and sequenced. The sequences were proofread, edited, and merged into composite sequences using Clustalx-1.83.1. The fungus was determined to be most closely related to Gloeophyllum trabeum by comparing it with related strains in GenBank. The GenBank accession numbers of KU-41 are JF682770-JF682771. 


\section{Corn stover pretreatment}

Another strain of G. trabeum NBRC6430 obtained from the Biological Resource Center (Chiba, Japan) was chosen to compare with the efficiency of corn stover pretreatment with G. trabeum KU-41. The biological pretreatment with G. trabeum KU-41 was carried out in $250 \mathrm{ml}$ Erlenmeyer flasks with $10 \mathrm{~g}$ corn stover powder and $40 \mathrm{ml}$ distilled water ( $80 \%$ moisture content) for a 20-day pretreatment. The other conditions were the same as described in the fungal screening. The release of glucose was determined by a Biosensor BF- 5 . The xylose from enzyme hydrolysis was determined by HPLC (HITACHI, RI detector, Shodex Asahipak NH2P-50 4E column; eluent: $\mathrm{CH}_{3} \mathrm{CN} / \mathrm{H}_{2} \mathrm{O}=75 / 25$; flow rate: $1 \mathrm{ml} /$ min; temperature: $30^{\circ} \mathrm{C}$ ).

\section{Chemical component analysis}

The lignin composition in corn stover pretreated with $G$. trabeum was determined by the method that determination of structural carbohydrates and lignin in biomass published by the National Renewable Energy Laboratory [60]. The carbohydrate composition was determined by total acidic hydrolysis followed by analysis of monomeric sugars by GC-MS [61]. Corn stover pretreated by G. trabeum was milled and then subjected to acid hydrolysis. A $300 \mathrm{mg}$ sample of pretreated corn stover was hydrolyzed with $72 \%$ sulfuric acid at $30^{\circ} \mathrm{C}$ for $4 \mathrm{~h}$. The secondary hydrolysis was performed after dilution with water to a $3 \%$ sulfuric acid concentration by autoclaving at $121^{\circ} \mathrm{C}$ for $60 \mathrm{~min}$. Then the hydrolysate was filtered through a glass filter. The acidic filtrate containing sugars was adjusted to a $\mathrm{pH}$ of 5-6 with barium hydroxide. The reduced monomeric sugars with $\mathrm{NaBH}_{4}$ were acetylated and then analyzed using a Shimadzu gas chromatography-mass spectrometer (GC-17A and GCMS-QP5050) with a glass capillary column, DB-5. The temperature program: $140^{\circ} \mathrm{C}$ for $3 \mathrm{~min} ; 140^{\circ} \mathrm{C}-280^{\circ} \mathrm{C}$, at a rate of $6^{\circ} \mathrm{C} / \mathrm{min} ; 280^{\circ} \mathrm{C}-320^{\circ} \mathrm{C}$, at a rate of $10^{\circ} \mathrm{C} / \mathrm{min} ; 320^{\circ}$ $\mathrm{C}$ for $5 \mathrm{~min}$.

\section{Cellulose crystallinity}

The crystallinity of the pretreated corn stover powder was measured by high resolution X-ray diffractometry (XD-D1 X-Ray diffractometer, Shimadzu, Japan). The measurement conditions were $40 \mathrm{kV}$ and $40 \mathrm{~mA}$. There were triplicate samples $a_{1}, a_{2}$, and $a_{3}$ pretreated with the same fungus, respectively. Each sample was scanned from $2 \theta=5^{\circ}$ to $35^{\circ}$ with a step size of 0.05 and tested three times to get the mean values à. Crystallinity (\%) was defined as $\left[\left(\mathrm{I}_{002}-\mathrm{I}_{\mathrm{am}}\right) / \mathrm{I}_{002}\right] \times 100 \%$, where $\mathrm{I}_{002}$ and $\mathrm{I}_{\mathrm{am}}$ are the maximum intensity at $2 \theta=22.6^{\circ}$ and the minimum intensity at $2 \theta=18.7^{\circ}$, respectively. The crystallinity value of corn stover pretreated with certain strain of fungus is mean \pm SD of $\overline{\mathrm{a}}_{1}, \overline{\mathrm{a}}_{2}$ and $\overline{\mathrm{a}}_{3}$.

\section{Initial adsorption capacity of cellulase}

A total of $0.21 \mathrm{~g}$ of commercial cellulase (Cellulosin T3, HBI Enzymes Inc.) was added to $0.3 \mathrm{~g}$ corn stover pretreated with G. trabeum KU-41 and G. trabeum NBRC6430. The corn stover pretreated with fungus without the addition of cellulase was used for the control. The mixture was added to $15 \mathrm{ml}, 100 \mathrm{mM}$ sodium acetate buffer $(\mathrm{pH}$ 4.6). These reactions were placed at $4^{\circ} \mathrm{C}$ for $90 \mathrm{~min}$ with $100 \mathrm{rpm}$ to reach adsorption equilibrium and were stopped by centrifugation at $8000 \mathrm{rpm}$ for $20 \mathrm{~min}$. Protein in the supernatant was measured by using the Bradford protein assay (Bio-Rad, Hercules, California, USA). Adsorbed cellulase was determined as the difference between the amount of protein initially added and the amount of un-adsorbed protein in the supernatant.

\section{Scanning electron microscopy (SEM)}

SEM pictures of untreated and pretreated corn stover (dried powder of particle size between $250 \mu \mathrm{m}$ and $300 \mu \mathrm{m})$ were taken at magnifications of 500 times using a JSM-5600LV1 scanning electron microscope at $5 \mathrm{kV}$. Prior to taking the pictures, the samples were sputtercoated with a thin layer of gold.

\section{Specific surface area determination}

The specific surface area of the pretreated corn stover sample was estimated by the Brunauer-Emmett-Teller (BET) method [62].

\section{Competing interests}

The authors declare that they have no competing interests.

\section{Authors' contributions}

ZG participated in the design of the study, performed all the laboratory scale experiments and took part in the interpretation of the results and the writing of the manuscript. TM carried out fungal identification and took part in the interpretation of the results. RK participated in the design of the study, took part in the interpretation of the results, and was the main author. All authors suggested modification to the draft, commented on several preliminary versions of the text, and approved the final manuscript. All authors read and approved the final manuscript.

\section{Acknowledgements}

The authors would like to thank Associate Professor T. Kitaoka and Associate Professor J. Matsumura of the Faculty of Agriculture, Kyushu University, Japan for their discussion and assistance throughout the investigation.

Received: 25 January 2012 Accepted: 19 March 2012

Published: 4 May 2012

\section{References}

1. Nelson RG, Walsh M, Sheehan JJ, Graham R: Methodology for estimating removable quantities of agricultural residues for bioenergy and bioproduct use. Appl Biochem Biotech 2004, 113:13-26. Numbers1-3).

2. Xing Y, Ma HC, Fan YT, Hou HW, Chen JR: Cellulose-hydrogen production from corn stalk biomass by anaerobic fermentation. Chinese Sci Bull 2009, 54:1434-1441

3. Hendriks ATWM, Zeeman G: Pretreatments to enhance the digestibility of lignocellulosic biomass. Bioresource Technol 2009, 100:10-18.

4. Yang B, Wyman CE: Pretreatment: the key to unlocking low-cost cellulosic ethanol. Biofpr 2008, 2:26-40. 
5. Keller FA, Hamilton JE, Nguyen QA: Microbial pretreatment of biomass potential for reducing severity of thermo-chemical biomass pretreatment. App/ Biochem Biotech 2003, 105:27-41.

6. Kumar R, Mago G, Balan V, Wyman CE: Physical and chemical characterizations of corn stover and poplar solids resulting from leading pretreatment technologies. Bioresour Technol 2009, 100:3948-3962.

7. Hakala TK, Maijala P, Konnb J, Hatakkaa A: Evaluation of novel wood-rot polypores and corticioid fungi for the decay and biopulping of Norway spruce (Picea abies) wood. Enzyme Microb Tech 2004, 34:255-263.

8. Zhang $X, Y u H$, Huang $H$, Liu Y: Evaluation of biological pretreatment with white rot fungi for the enzymatic hydrolysis of bamboo culms. Int Biodeterior Biodegrad 2007, 60:159-164.

9. Monrroy M, Ortega I, Ramirez M, Baeza J, Freer J: Structural change in wood by brown rot fungi and effect on enzymatic hydrolysis. Enzyme Microb Tech 2011, 49(5):472-477.

10. Ray MJ, Leak DJ, Spanu PD, Murphy RJ: Brown rot fungal early stage decay mechanism as a biological pretreatment for softwood biomass in biofuel production. Biomass Bioenerg 2010, 34(8):1257-1262.

11. Schilling JS, Tewalt JP, Duncan SM: Synergy between pretreatment lignocellulose modifications and saccharification efficiency in two brown rot fungal systems. Appl Microbiol Biot 2009, 84(3):465-475.

12. Taniguchi M, Suzuki H, Watanabe D, Sakai K, Hoshino K, Tanaka T: Evaluation of pretreatment with Pleurotus ostreatus for enzymatic hydrolysis of rice straw. J Biosci Bioeng 2005, 100:637-643.

13. Fissore A, Carrasco L, Reyes P, Rodriguez J, Freer J, Mendonca RT: Evaluation of a combined brown rot decay-chemical delignification process as a pretreatment for bioethanol production from Pinus radiata wood chips. J IND MICROBIOL BIOT 2010, 37(9):893-900.

14. Bobleter O: Hydrothermal degradation of polymers derived from plants. Prog Polym Sci 1994, 19:797-841.

15. Garrote G, Dominguez H, Parajo JC: Hydrothermal processing of lignocellulosic materials. Holz Roh Werkst 1999, 57:191-202.

16. Kohlmann KL, Westgate PJ, Sarikaya A, Velayudhan A, Weil J, Hendrickson R, Ladisch MR: Enhanced enzyme activities on hydrated lignocellulosic substrates. In ACS Symposium series No. 618. Edited by Saddler JN, Penner MH (Eds): Enzymatic Degradation of Insoluble Carbohydrates; 1995: 237255

17. Mosier N, Wyman C, Dale B, Elander R, Lee YY, Holtzapple M, Ladisch M: Features of promising technologies for pretreatment of lignocellulosic biomass. Bioresour Technol 2005, 96:673-686.

18. Goodell B, Jellison J, Liu J, Daniel G, Paszczynski A, Fekete F, Krishnamurthy S, Jun L, Xu G: Low molecular weight chelators and phenolic compounds isolated from wood decay fungi and their role in the fungal biodegradation of wood. J Biotechnol 1997, 53:133-162.

19. Hyde SM, Wood PM: A mechanism for production of hydroxyl radicals by the brown-rot fungus Coniophora puteana: Fe(III) reduction by cellobiose dehydrogenase and Fe(II) oxidation at a distance from the hyphae. Microbiology 1997, 143:259-266.

20. Koenigs JW: Hydrogen peroxide and iron: a proposed system for decomposition of wood by brown-rot basidiomycetes. Wood Fiber 1974 6:66-80

21. Jellison J, Connolly J, Goodell B, Doyle B, Illman B, Fekete F, Ostrofsky A: The role of cations in the biodegradation of wood by the brown rot fungi. Int Biodeter Biodegr 1997, 39:165-179.

22. Martinez D, Challacombe J, Morgenstern I, Hibbett D, Schmoll M, Kubicek $C P$, Ferreira P, Ruiz-Duenas F, Martinez AT, Kersten P, Hammel KE, Wymelenberg AV, Gaskell J, Lindquist E, Sabat G, BonDurant SS, Larrondo LF, Canessa P, Vicuna R, Yadav J, Doddapaneni H, Subramanian V, Pisabarro AG, Lavin JL, Oguiza JA, Master E, Henrissat B, Coutinho PM, Harris P, Magnuson JK, Baker SE, Bruno K, Kenealy W, Hoegger PJ, Kües U, Ramaiya P, Lucas S, Salamov A, Shapiro H, Tu H, Chee CL, Misra M, Xie G, Teter S, Yaver D, James T, Mokrejs M, Pospisek M, Grigoriev IV, Brettin T, Rokhsar D, Berka $R$, Cullen D: Genome, transcriptome, and secretome analysis of wood decay fungus Postia placenta supports unique mechanisms of lignocellulose conversion. PNAS 2009, 106:1954-1959.

23. Valášková $V$, Baldrian P: Degradation of cellulose and hemicelluloses by the brown rot fungus Piptoporous betulinus production of extracellular enzymes and characterization of the major cellulases. Microbiology 2006 , 152:3613-3622.

24. Rasmussen ML, Shrestha P, Khanal SK, Pometto AL, Van Leeuwen J: Sequential saccharification of corn stover fiber and ethanol production by the brown rot fungus Gloeophyllum trabeum. Bioresour Technol 2010, 101:3526-3533. Hans.

25. Laureano-Perez L, Teymouri F, Alizadeh $H$, Dale BE: Understanding factors that limit enzymatic hydrolysis of biomass. App/ Biochem Biotech 2005, 6A:1081-1099.

26. Thygesen A, Oddershede J, Lilholt $H$, Thomsen AB, Stahl K: On the determination of crystallinity and cellulose content in plant fibers. Cellulose 2005, 12:563-576.

27. Jeoh T, Ishizawa Cl, Davis MF, Himmel ME, Adney WS, Johnson DK Cellulase digestibility of pretreated biomass is limited by cellulose accessibility. Biotechnol Bioeng 2007, 98:112-122.

28. Change VS, Holtzapple MT: Fundamental factors affecting biomass enzymatic reactivity. App/ Biochem Biotech 2000, 84-86:5-37.

29. Kim S, Holtzapple MT: Effect of structural features on enzyme digestibility of corn stover. Bioresource Techno 2006, 97:583-591.

30. Grethlein HE: The effect of pore size distribution on the rate of enzymatic hydrolysis of cellulosic substrates. Nat Biotechnol 1985, 3:155-160.

31. Palonen $H$, Tjerneld F, Zacchi G, Tenkanen M: Adsorption of Trichoderma reesei $\mathrm{CBH}$ I and EG II and their catalytic domains on steam pretreated softwood and isolated lignin. J Biotechnol 2004, 107:65-72.

32. Grous WR, Converse AO, Grethlein HE: Effect of steam explosion pretreatment on pore size and enzymatic hydrolysis of poplar. Enzyme Microb Tech 1986, 8:274-280.

33. Marshall K, Sixsmith D: Some physical characteristics of microcrystalline cellulose. 1. Powders for pharmaceutical use. Drug Dev Commun 1974, 1:57-71

34. Gilkes NR, Jervis E, Henrissat B, Tekant B, Miller RC Jr, Warren RAJ, Kilburn $D G$ : The adsorption of a bacterial cellulase and its two isolated domains to crystalline cellulose. J Biol Chem 1992, 267:6743-6749.

35. Zhang YHP, Lynd LR: Toward an aggregated understanding of enzymatic hydrolysis of cellulose: noncomplexed cellulase systems. Biotechnol Bioeng 2004, 88:797-824.

36. Deshpande MV, Eriksson KE: Reutilisation of enzymes for saccharification of lignocellulosic materials. Enzyme Microb Tech 1984, 6:338-340.

37. Ishihara T, Ishihara M: Enzymatic hydrolysis of woods, IV. The effect of pretreatment with aqueous ammonia. Mokuzai Gakkaishi 1979. 25:804-807

38. Fan LT, Gharpuray MM, Lee YH: Evaluation of pretreatments for the enzymatic conversion of agricultural residues. Biotechnol Bioeng Symp 1981, 11:29-45.

39. Millett MA, Baker AJ, Satter LD: Pretreatments to enhance chemical, enzymatic and microbiological attack of cellulosic materials. Biotechnol Bioeng Symp 1975, 5:193-219.

40. Sudo K, Matsumura Y, Shimizu K: Enzymatic hydrolysis of woods, I. Effect of delignification on hydrolysis of woods by Trichoderma virida cellulase. Mokuzai Gakkaishi 1976, 22:670-676.

41. Stranks DW: Utilisation of aspen wood residues. For Prod J 1961, 11:288-292.

42. Wong KKY, Deverell KF, Mackie KL, Clark TA, Donald LA: The relationship between fiber porosity and cellulose digestibility in steam exploded Pinusradiata. Biotechnol Bioeng 1988, 31:447-456.

43. Gharpuray MM, Lee YH, Fan LT: Structural modification of lignocellulosics by pretreatments to enhance enzymatic hydrolysis. Biotechnol Bioeng 1983, 25:157-172.

44. Ruel K, Barnoud F, Eriksson KE: Ultrastructural aspects of wood degradation by Sporotrichum pulverulentum. Holzforschung 1982, 38:61-68.

45. Yelle DJ, Ralph J, Lu F, Hammel KE: Evidence for cleavage of lignin by brown rot basidiomycete. Environ. Microb 2008, 10:1844-1849.

46. Filley TR, Cody GD, Goodell B, Fellison J, Noser C, ostrofsky A: Lignin demethylation and polysaccharide decomposition in spruce sapwood degraded by brown rot fungi. Org Geochem 2002, 33:111-124.

47. Shimizu K, Usami K: Enzymatic hydrolysis of woods. Pretreatment of woods with acidic methanol-water mixture. Mokuzai Gakkaishi 1978, 24:632-637.

48. Shimizu K: Enzymatic hydrolysis of woods, V. Evaluation of papers and pulp-mill fiber residues as resources for sugar production. Mokuzai Gakkaishi 1980, 26:488-493.

49. Esteghlalian A, Bilodeau M, Mansfield SD, Saddler JN: Do enzymatic hydrolyzability and Simons' stain reflect the changes in the accessibility 
of lignocellulosic substrates to cellulase enzymes? Biotechnol Progr 2001, 17:1049-1054

50. Rivers DB, Emert GH: Factors affecting the enzymatic hydrolysis of municipal-solid-waste components. Biotechnol Bioeng 1988, 31:278-281.

51. Sasaki T, Tanaka T, Nanbu N, Sato Y, Kainuma K: Correlation between X-ray diffraction measurements of cellulose crystalline structure and the susceptibility to microbial cellulose. Biotechnol Bioeng 1979, 21:1031-1042.

52. Tanaka M, Taniguchi M, Morita T, Matsuno R, Kamikubo T: Effect of chemical treatment on solubilisation of crystalline cellulose and cellulosic wastes with Pelliculiiria filamentosa cellulase. J Ferment Technol 1979, 57:186-190.

53. Matsumura Y, Sudo K, Shimizu K: Enzymatic hydrolysis of woods, Effect of grinding and alkali treatment on hydrolysis of woods by Trichoderma viride cellulase. Mokuzai Gakkaishi 1977, 23:562-570.

54. Puri VP: Effect of crystallinity and degree of polymerisation on enzymatic saccharification. Biotechnol Bioeng 1984, 26:1219-1222.

55. Cohen R, Suzuki MR, Hammel KE: Processive endoglucanase active in crystalline cellulose hydrolysis by the brown rot basidiomycete Gloeophyllum trabeum. Appl Environ Microbiol 2005, 71:2412-2417.

56. Kondo R, Kurashiki K, Sakai K: In vitro bleaching of hard wood kraft pulp by extracellular enzymes excreted from white rot fungi in a cultivation system using a membrane filter. Appl Environ Microb 1994, 60:921-926.

57. Kondo R, Harazono K, Sakai K: Bleaching of hardwood kraft pulp with manganese peroxidase secreted from Phanerochaete sordida YK-624. Appl Environ Microb 1994, 60:4359-4363.

58. Goering HK, Van Soest PJ: Forage fiber analyses (apparatus, reagents, procedures, and some applications). In Agriculture Handbook 379. Edited by U.S. Department of Agriculture. Washington DC; 1970: 1-20.

59. Tien M, Kirk TK: Lignin peroxidase of Phanerochaete chrysosporium. Method Enzymol 1988, 161:238-249.

60. Sluiter A, Hames B, Ruiz R, Scarlata C, Sluiter J, Templeton D, Crocker D: Determination of Structural Carbohydrates and Lignin in Biomass. Technical Report NREL/TP-510-42618 2011.

61. Murai $K$, Uchida R, Okubo A, Kondo R: Characterization of the oil palm trunk as a material for bio-ethanol production (in Japanese). Mokuzai Gakkaishi 2009, 55:346-355.

62. Brunauer S, Emmett PH, Teller E: Adsorption of gases in multimolecular layers. J Am Chem Soc 1938, 60:309-319.

doi:10.1186/1754-6834-5-28

Cite this article as: Gao et al:: The pretreatment of corn stover with

Gloeophyllum trabeum KU-41 for enzymatic hydrolysis. Biotechnology for Biofuels 2012 5:28.

\section{Submit your next manuscript to BioMed Central and take full advantage of:}

- Convenient online submission

- Thorough peer review

- No space constraints or color figure charges

- Immediate publication on acceptance

- Inclusion in PubMed, CAS, Scopus and Google Scholar

- Research which is freely available for redistribution 